\title{
Testing Descriptive Hypotheses Regarding Sex Differences in the Development of Conduct Problems and Delinquency
}

Benjamin B. Lahey • Carol A. Van Hulle • Irwin D. Waldman • Joseph Lee Rodgers • Brian M. D'Onofrio · Steven Pedlow · Paul Rathouz • Kate Keenan

Erratum to: Journal of Abnormal Child Psychology, Vol. 34, No. 5, October 2006. DOI: 10.1007/s10802-006-9064-5

The mailing address for Joseph L. Rodgers listed in this paper is actually the address of his father. Here is Joseph L. Rodgers correct address:
Joseph Lee Rodgers

455 W. Lindsey

Department of Psychology University of Oklahoma

Norman OK 73019 